\title{
Albanian World-View: Co-Locativity as the Schematic Meaning of Albanian Verbal Prefix Bashke-
}

\author{
Rajdeep Singh ${ }^{1}$ \\ ${ }^{1}$ Department of Regional studies, University of Tehran, Tehran, Iran \\ Correspondence: Rajdeep Singh Department of regional studies, University of Tehran, Tehran, Iran. Tel: \\ 98-91-2858-6635. E-mail: rajdeep.singh@ut.ac.ir \\ Received: October 18, 2018 \\ Accepted: December 17, 2018 \\ Online Published: December 20, 2018 \\ doi:10.5430/elr.v7n4p36 \\ URL: https://doi.org/10.5430/elr.v7n4p36
}

\begin{abstract}
The traditional approach to verb prefixes is to consider them as bound morphemes without a real emphasis and analysis of their cognitive meaning. In this paper we use the concept schematic meaning which gathers verbs with different meaning while they share the same prefix. In our case, the Albanian bashke-prefix was chosen and its allomorph bashka-. In order to appreciate the schematic meaning concept and its application in the Albanian case, we considered the schematic meaning as the super-schema of bashke-prefix (co-prefix). This super-schema characterizes the metaphorical reading of the same prefix with different meaning which plays an important role in the semantics of abstract notions. This cognitive model helps to build a rather clear image of how the trajector and landmark inter-act as the basic units of spatial relations; the schematic brings about diverse meaning in a strict spatial frame-work.
\end{abstract}

Keywords: verbal prefix bashke-, schematic meaning, specific meaning, agentive trajectory, trajectory, landmark, super-schema

\section{Introduction}

Schematic and specific are introduced as important concepts for the cognitive grammar. They are crucial for an understanding of the relations between different categories, and the way these categories influence one another. Cognitive grammar operates with three types of linguistic units; the semantic and the phonological units, and one combinatory type, the symbolic units, which relates the two first types. These units are organized in a vertical hierarchical system where the super-ordinate schematic units are linked to the more specific subordinate units. It is important to have in mind that the concepts, schematic and specific, have something to do with the cognitive linguistics, more precisely the semantics of cognitive linguistics and grammar. Furthermore, one of the main principles operating in the cognitive grammar is that there is a continuum between lexicon and grammar, which affects wholly the way we approach to the classical divide between lexicology and grammar. In fact, in this case there is no boundary between the two and we can analyze the entire language syntax as a system which compromises both grammar and lexicon as its constructing units. If we follow the traditional interpretation of the word schema, then we encounter a vague, untidy, but yet general representation of things. On the other hand, the specific goes beyond the overall outlines and gets to the more core-like features inside the schema; indeed this is highly compatible with the semantics. In this article we will explore hidden aspects of the Albanian verbal prefix bashke- by the help of concepts such as schematic and specific.

There are different approaches to the prefixes, qualitative and quantitative, where both approaches are common and can be used in a wide range of analyses based on the conditions applied to them. Smolka and Eulitz (2018) investigate German verb prefixes in terms of their semantic transparency, how close their meanings are to the original verb. Semantic transparency tries to re-establish the link between main verbs and their derivative counter-parts and there are many quantitative methods available to conduct such investigation. However, an analysis based on the super-schema is a qualitative method of analyzing how the mind works out different meanings based on the previously formed schemata.

When we look at Albanian, we fast find out that it has some characteristics unique to it, such as the special use of linkers, very different from the Romance languages, though still comparable in some aspects. On the other hand, it has some resemblances to Slavic languages such as the active use of suffixes for the article. That is why it is hard to put Albanian into a cut-and-clear category. We all recall how the great linguist Roman Jackobson once stated that 
Roman Jakobson once stated that "the true difference between languages is not in what may or may not be expressed but in what must or must not be conveyed by the speakers" (Jakobson 1959/1971: 492). Put it another way, it's the language which provides its speakers with options to categorize and to frame the world in a specific manner. Among many linguistic items to investigate for a better understanding of the mental framing, verb prefixes are the best to capture this mental schema-formation. Just as Janda and Dickey (2017) states "ore continuous, allowing for scalar phenomena. Cognitive linguistics has generally focused on analyzing the semantic categories that constitute the meanings of linguistic units ...it views language as a dynamic emergent structure that is better characterized by patterns... One prominent way in which cognitive linguistics models relative continuity is by means of radial category structures in which a prototypical member of a category is related to relatively less prototypical members" (p.370). Prototypical quality, in our case, is best viewed as the main verb, without any prefix, this in turn will make it much easier to analyze how the mind constructs different meanings out of the prototypical verbs, or the schemata. We should keep in mind that the symbolic assembly, which helps us to work on different cognitive structures, is not to be confused with a one-to-one relationship between meaning and form; quite the opposite, meaning and form may be changing and variable. Linguistic elements that modify and present spatial relations have been an important source of inspiration for new theories in the cognitive sciences. In fact, both time and space set stage for the way we process information; implicit and explicit interpretations are formed by the inter-play between time-space linguistic elements. Spatial prepositions, adjective and verbal prefixes are important evidence of the whole time-space system in the cognitive grammar. Singh (2018) also analyzed the semantic and cognitive meaning of auxiliary verbs and in another study singh (2018) links the errors in learning Spanish to the cognitive load for Persian learners of Spanish. Furthermore, some authors, like Kostov (1939), claim that verbal prefixes only function in a way "to transform imperfective verbs to perfective verbs." (p. 120). Andrejčin (1944) expresses something similar, claiming that "in some cases the inherent meaning of the prefixes has bleached so much that the perfective verbs they form only differ from their imperfective counterparts in aspect.” (p. 198-199). Belaj (2008) discusses the prestructuralist, structuralist and traditional treatment of the matter. Whereas pre-structuralists were considered a cluster of purely homonymous relations derived from a single prefix in different verbs, structural semanticists were on the search of commonalities of semantics between different verbs with the same prefix. On the other hand, cognitive grammar considers the polysemous conceptual-semantic network as the product of verbs with the same prefix, organizing around prototypes. This brings the idea of the meaning chains where the semantic links connect members of a category. In fact, the meaning of one member is construed as an extension of the meaning of another member. This meaning chain can be thought of as the wave propagation through the space, where every small change in one element moves fast to other elements in the same category. This will result in a polysemous network of meanings linked indirectly into a chain.

"Meaning A is related to meaning B in virtue of some shared attribute(s), or other kind of similarity. Meaning B in turn becomes the source for a further extension to meaning C, which is likewise chained to meanings $\mathrm{D}$ and $\mathrm{E}$, and so on. The process may be illustrated

$$
\text { as follows: } \mathrm{A} \longrightarrow \mathrm{B} \longrightarrow \mathrm{C} \longrightarrow \mathrm{D} \text { etc.” (Taylor 1995: 108). }
$$

In fact, in cognitive grammar, the lexicon and grammar form a continuum chain of meaning; the lexicon and grammar are the extreme ends of this spectrum of meaning. Janda (2010) puts this better by saying "From the supraand segmental features of phonology through morphology, syntax, and discourse pragmatics, all of language shares the task of expressing meaning. This includes even idioms and "dead Cognitive Linguistics in the Year 20107 metaphors", which remain motivated within the system of a given language, and whose motivation can be made explicit" (p. 6). There have been studies that extensively investigated the roles of specific verbal prepositions to analyze the cognitive processing behind the meaning, metaphorically and literally. Tyler and Evans (2001) point out to the way cognitive linguistics takes a significantly different perspective on the nature of the mental lexicon. They assert that of primary importance is the notion of embodied meaning: the meanings associated with many individual lexemes are instantiated in memory not in terms of features, nor as abstract propositions, but rather as imagistic, schematic representations. Furthermore, they contend that "Such imagistic schemas are held to be embodied, in the sense that they arise from perceptual reanalysis of recurring patterns in everyday physical experience" (p. 725). They conclude that the distinction between constructed meanings and senses is important and should be taken into account. The former are constructed on-line in the course of constructing a conceptualization of a specific scene prompted by a particular utterance, whereas senses are instantiated in memory, and can be recruited for the process of conceptual integration. They assert that "while complex conceptualizations result from the process of conceptual integration taking account of motion and hence temporal frames, it does not follow that prepositions themselves code 
dynamism" (p. 762). Singh (2018) works on the semantics in the sacred and cultural context, stating that "Language behaves in a non-linear fashion and we see this non-linearity in the word formation and abstraction of the sacred words. Semantics is deeply related to the mental representation for concepts, but sometimes this linear one-to-one matching becomes distorted by the introduction of other phenomena" (Singh, 2018, p. 12). In one of the latest contributions to this debate over the semantics and space Tyler and Evans (2001) state the need for a "methodology ... that provides a rigorous and relatively consistent way of making judgements about whether a sense is distinct, and ... can be used in an intersubjective way" (p. 733) and they propopose one such methodology as principled polysemy approach. Šarić and Nedelcheva (2015) compare the verbal prefix o(b)- in two South Slavic languages, Croatian and Bulgarian, from a cognitive linguistic perspective by focusing on the problems arising when constructing the semantic network of this polysemous prefix and using extensive databases of verbs collected from dictionaries and a few corpora. They identify peripheral meanings, claiming that "in certain cases, the semantic categorization of prefixed verbs depends on the perspective of a particular language user or researcher... where subjectivity is a consequence of introspection and certainly an interfering factor in working out the semantic networks of prefixes" (p. 160). Kurani and Muho (2014) work on the similarities and differences of English and Albanian language in the morphological level, trying to compare different parts of speech of both languages. Linder (1981) proposed a somewhat new way of looking at the verbal particles up and out, where her analysis became a milestone in cognitive linguistic research on the relationship between language and space. She asserts that Space Grammar recognizes a continuum between so-called syntactic and lexical structures based on degrees of analyzability, productivity, and regularity. She proposes a single super-schema, or a single super-schematic feature common to all the meanings of the particle out. However, she later considers some basic super-schemas with the highest level of abstraction and uses these basic super-schemas to arrive to the more specific meanings. Another study looks at the spatial prepositions and their important conceptual meaning which interact with the grammar (Singh, 2018). In languages that are not related such as Persian and Hausa, still the prefixes and the way they relate the altered verbs with the original ones play an important role, showing a rather universal concept behind their semantics (Singh, 2018). Belaj (2008) proposes a novelty and argues for "the shifting of the highest relevant level of abstraction one step up the scale of schematicity" and he maintains that "This level will come to coincide with the level of the common superschema... which abstracts away features of the more specific semantic groups and furnishes them all with relevant, common meaning" (p. 126). In our study we follow the same direction; here we will use the Albanian verbal prefix bashke- to investigate the semantic link in the meaning chain of different verbs with the same prefix bashke- which is an important, highly productive verbal prefix in Albanian. Another study investigates the changes in language which is related to the introduction of a new language, pointing out to the prefixes and the way they can be altered during the language change period (Singh, 2018). One study works on the gender differences between English and Albanian and states that "The contrast of gender between two languages are e.g: the cases (five in Albanian with different endings and two in English), definite and indefinite nouns (the masculine nouns for Albanian language has some engings: -i, -it, -in, -it, -u, -un, -ut, for feminine -e,-a, -ja, -je, -s, -së, -në, or for neuter nouns with $-\mathrm{i}$, -it and for indefinite nouns is: /një/" (Millaku,2016, P.1).This shows that Albanian has a rich morphological structure and the complexity of its internal word structure should be taken into consideration. Singh (2018) investigates the negative-prefixing phenomenon in Russian and shows how the negative-prefixing has a cognitive load on the Russian learners. Xhina (2013) considers prefixes to fall semantically into one of the following categories: prefixes of attitude, reservative and deprivative prefixes and negative prefixes. Xhina states that "Prefixes in Albanian language are quite less in quantity, only one third of suffixes. Moreover, they do not have the same level of productivity as suffixes do, though prefixation remains a very important word-formation process especially in creating technical and scientific terminology" (Xhina, 2013, p.256). Despite this, prefixes still play a very important role in the metaphoric and cognitive sense and are an important tool to analyze abstract ideas through spatial relations. Xinha also points out that "When the word class changes, the prefix is completely attached to the base and the final base vowel drops, for e.g.: përbuz.v - to despise (buzë, n.), shfaq v. to appear - (faqe, n.), përgjak to bleed (gjak); the prefixes: për-, sh-, are attached to the nouns buzë, faqe, gjak and have formed verbs, changing the word class" (Xhina, 2013, p. 257). Singh (2018) also points out to the importance of semantics in the so-called "BASKET VERB" which contains all of the information necessary to form the sentence.

\subsection{Basic Spatial Semantic Concepts}

Before going into the depth of our analysis, we should further point out to the landmark and trajectory concepts since we will use them heavily in our analysis. As Šarić and Nedelcheva (2015) defines "Image schemas in cognitive linguistics depict two basic entities: a trajector (TR) and a landmark (LM... and another salient entity in a relational 
predication, prototypically providing a point of reference for locating the TR" (p. 150). In other words, landmark is "is the reference entity in relation to which the location or the trajectory of motion of the trajector is specified" (Zlatev, 2007, p. 8). Image schema is also further defined as "a cognitive representation comprising a generalization over perceived similarities among instances of usage" (Barlow \& Kemmer 2000: viii).

\section{Albanian Bashke-Prefix and the Cognitive Meaning}

The prefix bashke- is among the highly productive verbal prefixes in Albanian. Compared to other Albanian prefixes bashke- has only two allomorphs, namely bashka and bashke-though bashka is so rare to be used and bashke is almost always used to form new verbs. In fact, it appears almost always with the same form, whereas in other languages like Croatian there are many allomorphs for spatial prefixes; for example the Croatian pred- has two allomorphs pred-and pret- (BELAJ, 2010). Cognitive schemata are widely used in languages, and we can find them in languages as distant as Portuguese and Persian. It is therefore important to note the productivity ratio of some of the spatial prefixes. Albanian bashke-prefix is one of the most productive prefixes in Albanian, as it is co-prefix in English with all its allomorphs such as con- and com-. Figure 1 shows a general perspective of this super-schema representation.

Given the high productivity of the prefix, verb groups have consistently high members. Before we turn to our analysis, a few comments are in order. The four groups of verbs, representing distinct elaborations of the superschema have different prototypicality. As Langacker (1991) stated, We shall treat as more prototypical those verbs whose trajectors and landmarks are ranked higher on the scale of concreteness (specificity) [ANIMATE people > animals ANIMATE] >[INANIMATE physical objects > abstract entities INANIMATE], (Langacker, 1991, p. 322). Beyond the fact that concrete trajectors and landmarks are readily accessible, we shall note that "Trajector's concreteness (the sense of physical relations between trajectory and landmark) is proportional to the awareness of its prototypical movement in space" (belaj, 2008, p. 126). The superschema of co-locativity is illustrated below, in Figure 1, while more specific cases will be described and illustrated in the remainder of this paper. It is important to think of the co-locativity as one of the most fundamental spatial prepositions which is in direct connection to the cognitive schema formation. In fact, many languages use co-locativity in order to describe much more complex ideas through space metaphors. Therefore, it is not a surprise that some languages, including Albanian, use this special preposition in the verb formation.

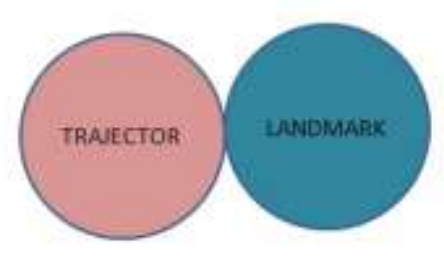

Figure 1. superschema of co-locativity

\subsection{Bashkëjetoj------ (Coexist)}

One reading of the schematic meaning of co-locativity in the first group of verbs derives from the position of the trajector relative to a collective human landmark. Here the trajectory is side by side the landmark. However, an interesting feature is that both the landmark and trajectory are living creatures, being able to move and change their places. Therefore, this group has the metaphorical reading as well. Here, we are primarily concerned basic spatial relation SIDE BY SIDE as the source of metaphor INTER-DEPENDENCY. This metaphor allows us to construe an inter-dependent alive system where one trajector is dependent on the landmark and vice-versa. Figure 2 and Figure 3 illustrate the conceptualization of more abstract notion of inter-dependency. 


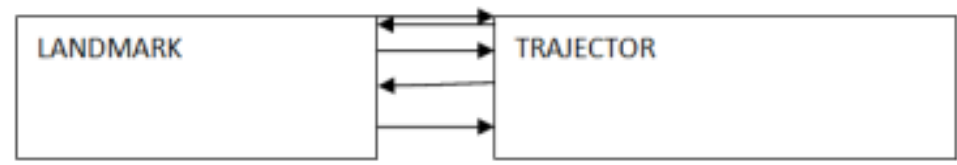

Figure 2. Landmark and trajectory for co-prefix

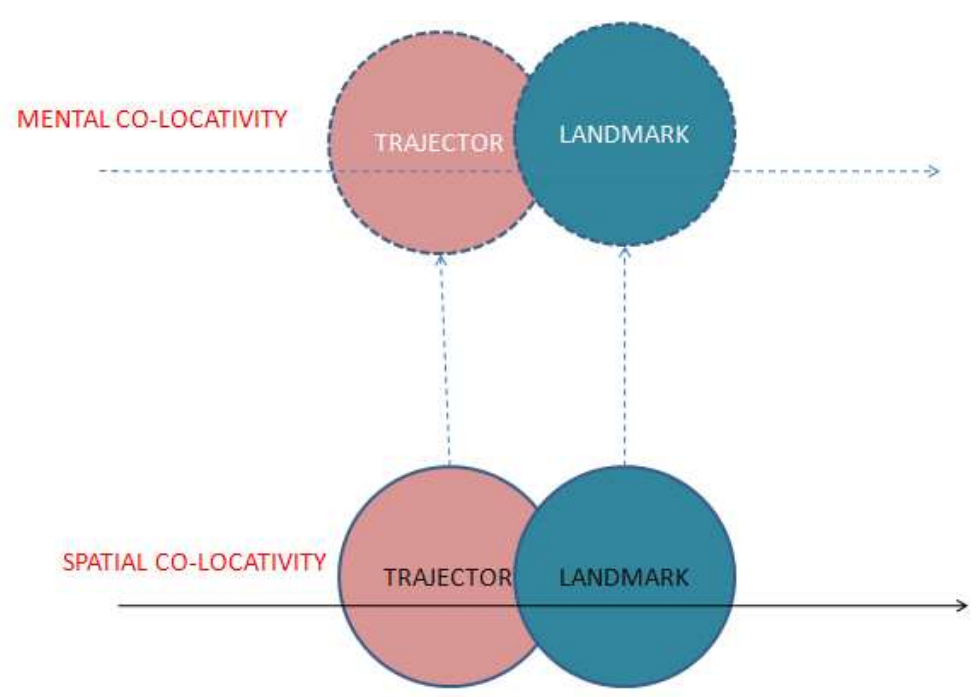

Figure 3. Schema of interdependency bashke-prefix

\subsection{Bashkëngjis.... (Attach)}

Here the agentive trajectory moves towards another agentive trajectory which is also the landmark. The interesting point is that both trajector and landmark can be animate or inanimate. In other words, there is a complete freedom regarding the animate quality for landmark and trajector. Here, the main verb is ngjis which means to fall; we definitely see how the notion of falling is associated with the co-prefix in order to show the dynamics of attachment. In a sense, Albanian is unique in forming this type of metaphoric meaning of attachment with the movement. The metaphoric reading relates to the CONNECTION. This metaphoric analysis is illustrated in Figure4. 


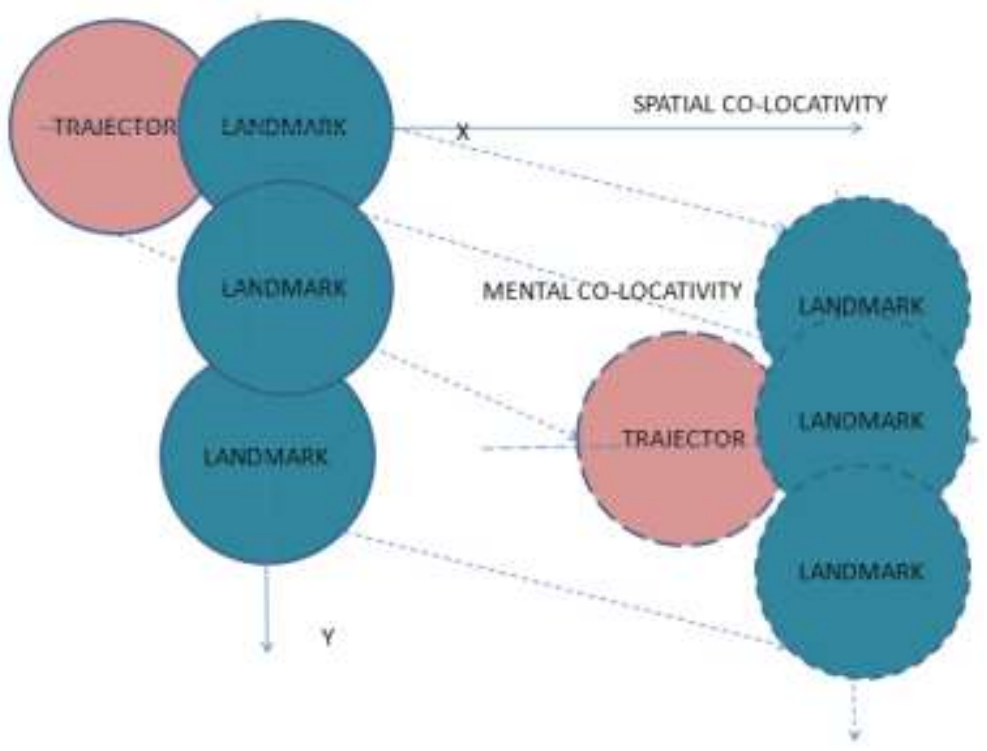

Figure 4. Schema of connection for co-prefix

\subsection{Bashkëveproj...(Inter-Act)}

In case of verbs such as bashkeveproj (inter-act) the agentive trajector juxtaposes another agentive trajectory which is also the landmark. Here, the metaphoric reading is EXHANGE; trajectory exchanges something with the landmark. We can think of the togetherness as metaphor of EXCHANGE, where being close helps to create a RELATIONSHIP between landmark and trajector. Figure5 illustrates the metaphoric reading of this kind of verbs. In fact, when landmark and trajectory are close enough to cooperate and form connection, we can have the end-result of EXCHANGE. This brings us to the source for exchange which is the closeness and is expressed by the co-prefix.

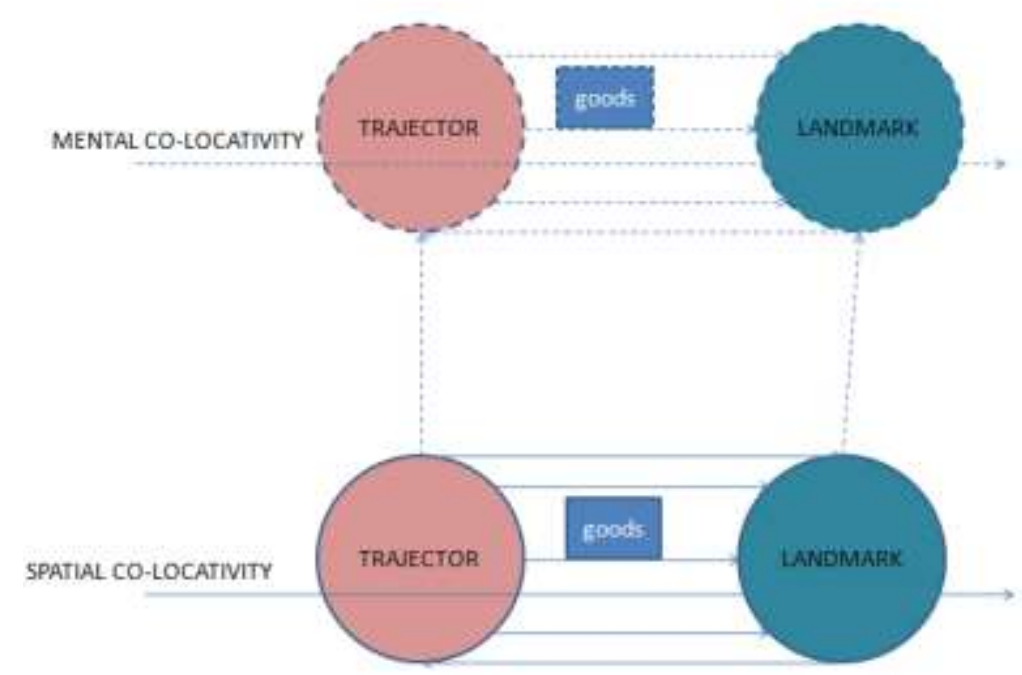

Figure 5. Schema of exchange for co-prefix 


\section{Conclusion and Discussion}

A semantic analysis of the bashke-prefix in Albanian illustrated the rather complex structure of super-schema which affects the way we categorize the world. In Albanian case, there were many instances of metaphoric readings. This is an important evidence of abstraction in the mind and meaning transformation based on the initial spatial relations. In fact, the co-prefix is an important bearer of the metaphor formation in Albanian language and it sheds light on the way the mind uses spatial relations to build a clear but yet complex meaning. This kind of analysis has already proved applicable to Croatian, Italian prefixes and to pre-fixes in other languages as well. The notion of space as cognitive mapping to the constructed meanings is an important one and we saw how the mental real is fed by the spatial concept. In fact, we see that language is like a molding pot that different spatial experiences are formed as initial experience schemata and then they translate the abstract notions to the understandable and simplified notions. Another interesting phenomenon in Albanian language is the way meaning is manipulated by the prefixes such as co-prefix as it even shows notions as abstract as goods exchange by the simple relation of closeness. In this paper we also took note of interesting metaphoric readings of bashke-prefix, involving a sense of strong movement in the final interpretation. Albanian is one of the most important languages in its ability to form different meaning from the main verb by the use of prefixed and it may offer great insight to the way mind frame and view the world. Furthermore, our approach, which takes into account both the semantic components, allowed us to create a much more finely-grained semantic network where the senses and schemata are presented in a qualitative way, much closer to the reality compared to the previous quantitative projects.

\section{References}

Andrejčin, L. (1944). Osnovna bălgarska gramatika. Sofia: Hemus. Retrieved from: https://www.duo.uio.no/bitstream/handle/10852/65450/The\%2Bverbal\%2B\%2Bprefix\%2Bu-\%2BFINAL.pdf?s equence $=4 \&$ isAllowed $=\mathrm{y}$

Barlow, M. \& Kemmer, S. (2000). Introduction. Barlow M., S. Kemmer, eds. Usage-Based Models of Language. Stanford: Center for the Study of Language and Information Press. Retrieved from: https://www.unm.edu/ jbybee/downloads/Bybee2000PhonologyLexicon.pdf

Belaj, B. (2008). Pre-locativity as the schematic meaning of the Croatian verbal prefix pred-. Jezikoslovlje, 9, 1-2, 123-140. Retrieved from: https://hrcak.srce.hr/file/48552

Janda, L., A. (2010). Cognitive linguistics in the year 2010. In International journal of cognitive linguistics. 1.1. 1-30. Retrieved from: ansatte.uit.no/laura.janda/mypubs/Janda-PC\%20proofread\%20by\%20Janda.doc

Janda, L., A. \& Dickey, S., M. (2017). Cognitive Linguistics: A Neat Theory for Messy Data. Journal of Slavic Linguistics, 25(2), 369-387. https://doi.org/10.1353/js1.2017.0014

Kurani,A \& Muho,A (2014). A morphological comparative study between Albanian and English language. European Scientific Journal. Retrieved from: http://eujournal.org/index.php/esj/article/viewFile/4705/4495

Langacker, R., W. (1991). Foundations of Cognitive Grammar, 2. Stanford: Stanford University Press. https://doi.org/10.3138/cmlr.46.3.573

Lindner, Susan J. (1981). A Lexico-Semantic Analysis of English Verb-Particle Constructions with UP and OUT. $\mathrm{PhD}$ dissertation, University of California, San Diego. Retrieved from: https://elibrary.ru/item.asp?id=7343465

Millaku,S. (2016). The contrast of the gender between Albanian and English language. International Journal of Thales Educational Sciences (THEDS) ISSN (print), 2(1), Turqi. https://doi.org/10.2139/ssrn.3041938

Šarić, L. \& Nedelcheva, S. (2015). The verbal prefix o(b)- in Croatian and Bulgarian: The semantic network and challenges of a corpus-based study. Suvremena 226 Darko Matovac: Obilježja upotrebe i znaÿenja prijedloga mimo u hrvatskom jeziku lingvistika, 41(80), 149-179. Retrieved from: https://hrcak.srce.hr/index.php?show=clanak\&id_clanak_jezik=221073

Singh, R. (2018). Derivational Grammar Model and Basket Verb: A Novel Approach to the Inflectional Phrase in the Generative Grammar and Cognitive Processing. English Linguistics Research, $7(2)$. https://doi.org/10.5430/elr.v7n2p9

Singh, R. (2018). A Cognitive Approach to the Semantics in the Sacred Context: Semantic and Symbolic Function of Sacred Words. English Linguistics Research, 7(3). https://doi.org/10.5430/elr.v7n3p1 
Singh, R. (2018). Norwegian and Persian spatial prepositions: a novel comparative and syntactic approach to the spatial prepositions. KAAV international journal of English, literature, and linguistics, 5, 1-8. Retrieved from: http://www.kaavpublications.org/journals/journal-5/article/article-1788.pdf

Singh, R. (2018). Areas of errors and difficulty for persian learners of spanish caused by the sound system differences between persian and spanish: a phonetic approach to inter-lingual system. KAAV international journal of English, literature, and linguistics, 5, 1-8. Retrieved from: http://www.kaavpublications.org/journals/journal-5/abstract/abstract-1996.pdf

Singh, R. (2018). Russian and Negative Prefixing: A Cognitive-Semantic Approach to the Negative Adjective Prefixing in Russian, Spanish, Persian, and English. English Linguistics Research, 7(4). https://doi.org/10.5430/elr.v7n4p7

Singh, R. (2018). Auxiliary Verbs in Serbo-Croatian, French, Persian, Spanish and English: A Cognitive-Semantic Approach to the Auxiliary Verb Usage and Passive Voice. English Linguistics Research, 7(3). https://doi.org/10.5430/elr.v7n3p34

Singh, R. (2018). Language change and directionality: A novel model for language change in Persian and Iranian languages from the sociolinguistic perspective. KAAV International journal of English, Literature, and linguistics, 5, 1-8. Retrieved from: http://www.kaavpublications.org/journals/journal-5/article/article-1876.pdf

Singh, R. (2018). Error Analysis of Persian Learners of Hausa Language: Cognitive Approach to Errors. Journal of Literature, Languages and Linguistics, 45, 10-15. Retrieved from: https://iiste.org/Journals/index.php/JLLL/article/view/42853/44147

Smolka, E. \& Eulitz, C. (2018). Psycholinguistic measures for German verb pairs: Semantic transparency, semantic relatedness, verb family size, and age of reading acquisition. Behavior Research Methods, 1-23. https://doi.org/10.3758/s13428-018-1052-5

Tyler, A. \& Evans, E. (2001). 'Reconsidering prepositional polysemy networks: The case of over'. Language, 77(4), 724-65. https://doi.org/10.1353/lan.2001.0250

Xhina, O. (2013). Prefixation in English and Albanian languages. Academic Journal of Interdisciplinary studies, special issue, 2(8). https://doi.org/10.5901/ajis.2013.v2n8p253

Zlatev, J. (2007). Spatial semantics. In H. Cuyckens D. Geeraerts, editor, The Oxford Handbook of Cognitive Linguistics, chapter 13, 318-350. https://doi.org/10.1093/oxfordhb/9780199738632.013.0013 